\title{
Pengaruh Bukti Fisik, Reliabilitas, Assurance, Daya Tanggap Dan Empati Terhadap Loyalitas Pelanggan Emeralda Golf
}

\author{
Melani, Sujana dan Gen Gen Gendalasari \\ Program Studi Manajemen, Institut Bisnis dan Informatika Kesatuan \\ Bogor, Indonesia
}

E-Mail: melani@ibik.ac.id
Golf Tourism

Customers

Satisfcation

\section{ABSTRAK}

Banyaknya pesaing dalam perusahaan sejenis membuat setiap klub golf berlomba-lomba untuk memberikan pelayanan dan fasilitas yang menunjang guna kepuasan para golfer dan mendorong agar setiap golfer menjadi loyal terhadap produk atau jasa yang ditawarkan dari masing-masing lapangan golf tersebut. Tujuan dari penelitian ini adalah (1) Untuk mengetahui seberapa besar pengaruh Bukti Fisik terhadap Loyalitas Pelanggan (2) Untuk mengetahui seberapa besar pengaruh Reliabilitas terhadap Loyalitas Pelanggan. (3) Untuk mengetahui seberapa besar pengaruh Assurance terhadap Loyalitas Pelanggan. (4) Untuk mengetahui seberapa besar pengaruh Daya Tanggap terhadap Loyalitas Pelanggan. (5) Untuk mengetahui seberapa besar pengaruh Empati terhadap Loyalitas Pelanggan. (6) Untuk mengetahui seberapa besar pengaruh Bukti Fisik, Reliabilitas, Assurance, Daya Tanggap dan Empati secara bersama-sama terhadap Loyalitas Pelanggan. Jumlah responden dalam penelitian ini berjumlah 100 responden yang diambil dari pelanggan Emeralda Golf. Data penelitian diolah menggunakan SPSS de ngan analisis regresi berganda. Hasil dari penelitian ini adalah: (1) Bukti Fisik berpengaruh positif dan signifikan terhadap Loyalitas Pelanggan pada lapangan golf Emeralda. (2) Reliabilitas berpengaruh positif dan signifikan terhadap Loyalitas Pelanggan. (3) Assurance tidak berpengaruh positif dan signifikan terhadap Loyalitas Pelanggan pada lapangan golf Emeralda. (4) Daya Tanggap berpengaruh positif dan signifikan terhadap Loyalitas Pelanggan.

(5) Empati tidak berpengaruh positif dan signifikan terhadap Loyalitas Pelanggan.

(6) Bukti Fisik, Reliabilitas, Assurance, Daya Tanggap dan Empati berpengaruh secara bersama-sama terhadap Loyalitas Pelanggan. Artinya semakin baik Bukti Fisik, Reliabilitas, Assurance, Daya Tanggap dan Empati maka Loyalitas Pelanggan semakin tinggi.

Kata Kunci: bukti fisik, reliabilitas, assurance, daya tanggap, empati, loyalitas pelanggan, wisata golf.

\section{PENDAHULUAN}

Pada saat ini pertumbuhan ekonomi global semakin mengarah pada persaingan khususnya untuk perusahaan sejenis. Banyaknya pesaing dalam perusahaan sejenis membuat setiap klub golf berlomba-lomba untuk memberikan pelayanan dan fasilitas yang menunjang guna kepuasan para golfer dan mendorong agar setiap golfer menjadi loyal terhadap produk atau jasa yang ditawarkan dari masing-masing lapangan golf tersebut. PT. Karabha Digdaya

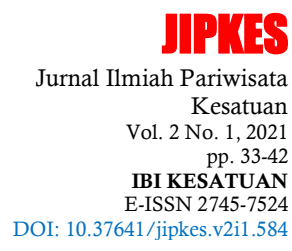


Golf Tourism

Customers

Satisfaction

34

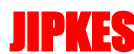

Jurnal Ilmiah Pariwisata

Kesatuan

Vol. 2 No. 1,2021

pp. 33-42

IBI KESATUAN

E-ISSN 2745-7524

DOI: 10.37641 /jipkes.v2i1.584
(Emeralda Golf Club) Cimanggis Depok merupakan perusahaan yang bergerak di bidang jasa khususnya penyedia jasa lapangan golf. Berbagai fasilitas telah disediakan oleh perusahaan ini antara lain, yaitu: Golf Cart, Golf Shop, Driving Range, Putting Green, Locker Room, Restaurant, Vip room, Meeting room, Game room, Spa, Sauna \& Massage, Weding, photo taking, Exhibition space. Selain menyediakan beberapa fasilitas, PT. Karabha digdaya (Emeralda Golf Club) Cimanggis depok juga memliki 3 course (jenis lapangan) antara lain : River course, Lake course, dan Plantation course. Selain menyediakan beberapa fasilitas dan jenis lapangan kepada para pelanggan atau golfernya, perusahaan ini juga memberikan pelayanan yang maksimal untuk para pelanggannya. Karena, dengan memberikan pelayanan yang baik akan memberikan kepuasan tersendiri dihati para pelanggannya dimana dengan kepuasan itulah pelanggan menjadi loyal atau setia dan tidak akan berpindah ke lain hati.

PT. Karabha Digdaya merupakan salah satu lapangan golf yang memiliki lahan terluas. Terbukti standar dari lapangan golf biasanya adalah menyediakan 18 hole lapangan tetapi PT. Karabha Digdaya (Emerlda Golf Club) memiliki 27 hole lapangan. Luasnya lapangan golf yang dimiliki PT. Karabha Digdaya tidak menjamin pelanggan akan selalu ramai. Ditahun 2018 pelanggan yang berkunjung mengalami penurunan dari tahun sebelumnya. Pramu golf dapat dikatakan sebagai perwakilan dari sebuah club golf, yang dimana kepuasan pelanggan juga ditentukan oleh seorang Pramu golf tersebut. Sehingga perusahaan melakukan berbagai cara agar pramu golf yang dimiliki memberikan kepuasan terhadap pelanggan. Mulai dari diberikan training khusus, beauty class, dan selalu dilakukan pengawasan terhadap sikap dan penampilan, agar tercapainya kepuasan pelanggan. Sehingga, pelanggan terus tetap menjadi pelanggan setia yang nantinya akan menimbulkan loyalitas dibenak pelanggan. Sebab itu, perlu adanya survei kepuasan pelanggan untuk mengetahui kabutuhan dan keinginan pelanggan seperti apa terhadap perusahaan, sehingga pelanggan tersebut akan menjadi loyal kepada perusahaan.

Golf Course atau lapangan golf merupakan hal penting yang harus diperhatikan oleh perusahaan. Karena apabila lapangan golf tidak dirawat dan diperhatikan dengan baik maka akan mengalami kerusakan jangka pendek dan jangka panjang dan ketika lapangan golf mengalami kerusakan atau kurang baik maka pelanggan pun tentunya tidak nyaman bermain golf ditempat tersebut. Daya tanggap dari petugas perusahaan sangatlah penting dimana pelanggan berkomunikasi secara langsung dengan perwakilan perusahaan. Sehingga hampir di setiap lapangan golf petugas diberikan training khusus bagaimana melayani pelanggan dengan maksimal serta diberikan penyuluhan khusus tentang kemungkinan yang bisa terjadi selama proses pelayanan jasa berlangsung. Tidak jarang pelanggan ketika proses pelayanan jasa berlangsung meminta menggantkan petugas lapangan dikarenakan pelayanan petugas kurang memuakan sehingga akan berdampak negatif terhadap pelanggan dan perusahaan. Sedari awal dari setiap perusahaan golf manapun menyuluhkan kepada setiap petugas lapangan agar melayani pelanggan dengan tulus hati dan ikhlas. Dari persaingan inilah perusahaan selalu mencoba untuk lebih mendekatkan dengan para petugas lapangan dengan mengadakan acara outing ataupun lainnya sehingga petugas merasa gembira untuk bekerja kepada perusahaan. Walau sudah dilakukan cara seperti masih banyak yang perlu dibenahi agar pelanggan tidak mengganti petugas lapangan ketika proses pelayanan jasa berlangsung. 
Lokasi penelitian dilakukan di PT. Karabha Digdaya (Emeralda Golf Club).

Dalam penelitian ini, data primer didapat melalui kuesioner yang dibagikan kepada Pemain Golf dengan pertanyaan-pertanyaan seperti usia, jenis kelamin, pekerjaan dan lain-lain serta persepsi responden tentang Bukti Fisik $\left(\mathrm{X}_{1}\right)$, Reliabilitas $\left(\mathrm{X}_{2}\right)$, Assurance $\left(\mathrm{X}_{3}\right)$, Daya Tanggap $\left(\mathrm{X}_{4}\right)$, dan Empati $\left(\mathrm{X}_{5}\right)$ terhadap Loyalitas Pelanggan (Y). Data sekunder merupakan data yang sudah jadi yaitu berupa pengertian-pengertian teoritis yang diperoleh dengan mempelajari bukubuku serta literatur-literatur lain yang mempunyai hubungan dengan pengaruh Bukti Fisik, Reliabilitas, Assurance, Daya Tanggap, Empati dan Loyalitas Pelanggan yang merupakan bahan yang dibutuhkan penulis sebagai acuan untuk melakukan penelitian ini. Sampel Penelitian ini berjumlah 100 orang responden yang ditetapkan dengan metode simple purposive sampling. Data dianalisis menggunakan analisis regresi berganda.

\section{HASIL DAN PEMBAHASAN}

Emeralda Golf selalu berusaha untuk terus meningkatkan kepuasan pelanggan mulai dari perawatan yang maksimal lapangan golf, fasilitas lain, hingga penampilan petugas pemandu golf di lapangan. Terbukti Emeralda Golf selalu digunakan menjadi tempat ajang olahraga tournament tingkat International karena memiliki standar lapangan golf yang baik. Dari tahun 2016 ke tahun 2017 Emeralda Golf mengalami kenaikan jumlah pelanggan yaitu dari 67,555 pelanggan menjadi 71,333 pelanggan dengan total pendapatan dari pelanggan adalah sekitar Rp. 44.614.537.000.

\section{Profil Responden}

Data responden berdasarkan usia data yang diperoleh pada penelitian ini sebanyak 11 orang (11\%) berusia diantara 20-30 tahun, 26 orang $(26 \%)$ berusia diantara 31-40 tahun, 55 orang (55\%) berusia diantara 41-50 tahun, dan 8 orang $(8 \%)$ berusia diatas 50 tahun. Dengan ini menyatakan bahwa responden paling banyak berumur diantara 41-50 tahun yaitu sebanyak 55\%. Data responden berdasarkan pekerjaan yang diperoleh pada penelitian ini dapat diketahui bahwa sebanyak 2 orang $(2 \%)$ responden adalah mahasiswa, 2 orang $(2 \%)$ responden responden adalah pegawai negeri, 43 orang (43\%) responden adalah seorang wiraswasta dan 53 orang (53\%) responden memiliki pekerjaan lainnya. Dengan ini menyatakan bahwa responden paling banyak adalah responden yang memiliki pekerjaan lainnya sebanyak 53\%. Data responden berdasarkan Rutinitas Bermain Golf yang diperoleh pada penelitian ini dapat diketahui bahwa sebanyak 17 orang $(17 \%)$ responden bermain 1 bulan sekali, sebanyak 58 orang $(58 \%)$ responden bermain 1 bulan 4 kali, 25 orang (25\%) responden bermain 1 bulan diatas 5 kali. Dengan ini menyatakan bahwa responden dengan rutinitas 1 bulan 4 kali adalah yang terbanyak yaitu $58 \%$.

\section{Uji Kualitas Data}

Untuk menguji kualitas data penelitian, telah dilakukan uji validitas, reliabilitas dan uji asumsi klasik. Validitas data diukur dengan memperhatikan perbandingan nilai r-product moment hitung dan tabelnya untuk setiap indikator masing-masing variabel. Berdasarkan hasil analisis untuk variabel Bukti Fisik diperoleh r-product moment hitung untuk pernyataan ke 1 yaitu 0,903 ; pernyataan ke 2 yaitu 0,827 ; pernyataan ke 3 yaitu 0,873 ; pernyataan ke 4 yaitu 0,922 dan pernyataan ke 5 yaitu 0,928 . Hasil r-product moment hitung di atas menunjukan

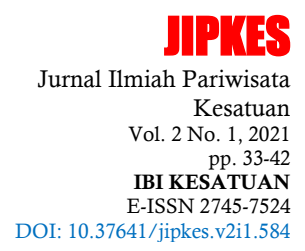


Golf Tourism

Customers

Satisfaction

36

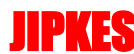

Jurnal Ilmiah Pariwisata

Kesatuan

Vol. 2 No. 1,2021

pp. 33-42

IBI KESATUAN

E-ISSN 2745-7524

DOI: $10.37641 /$ jipkes.v2i1.584 hasil lebih besar dari $r$-product moment tabel, $n=30, \alpha=5 \%$ yaitu 0,361 dan nilai signifikansi dibawah 5\% sehingga kesimpulannya adalah valid dan dapat digunakan untuk penelitian selanjutnya. Untuk variabel reliabilitas diperleh nilai r-product moment hitung untuk pernyataan ke 1 yaitu 0,911 ; pernyataan ke 2 yaitu 0,880 ; pernyataan ke 3 yaitu 0,896 ; pernyataan ke 4 yaitu 0,895 dan pernyataan ke 5 yaitu 0,880 . Hasil r-product moment hitung tersebut menunjukan hasil lebih besar dari $r$-product moment tabel, $\mathrm{n}=30, \alpha=5 \%$ yaitu 0,361 dan nilai signifikansi dibawah 5\% sehingga kesimpulannya adalah valid dan dapat digunakan untuk penelitian selanjutnya.

Kemudian untuk variabel assurance, diperoleh nilai $r$-product moment hitung untuk pernyataan ke 1 yaitu 0,916 ; pernyataan ke 2 yaitu 0,937 ; pernyataan ke 3 yaitu 0,891; pernyataan ke 4 yaitu 0,867 . Hasil r-product moment hitung di atas menunjukan hasil lebih besar dari r-product moment tabel, $\mathrm{n}=30, \alpha=5 \%$ yaitu 0,361 dan nilai signifikansi dibawah 5\% sehingga kesimpulannya adalah valid dan dapat digunakan untuk penelitian selanjutnya. Sedangkan untuk variabel daya tanggap diperoleh nilai r-product moment hitung untuk pernyataan ke 1 yaitu 0,690; pernyataan ke 2 yaitu 0,892; pernyataan ke 3 yaitu 0,904. Hasil r-product moment hitung di atas menunjukan hasil lebih besar dari r-product moment tabel, $\mathrm{n}=30, \alpha=5 \%$ yaitu 0,361 dan nilai signifikansi dibawah $5 \%$ sehingga kesimpulannya adalah valid dan dapat digunakan untuk penelitian selanjutnya.

Lalu untuk variabel empati diperoleh nilai r-product moment hitung untuk pernyataan ke 1 yaitu 0,697 ; pernyataan ke 2 yaitu 0,786 ; pernyataan ke 3 yaitu 0,511. Hasil r-product moment hitung di atas menunjukan hasil lebih besar dari $r$ product moment tabel, $\mathrm{n}=30, \alpha=5 \%$ yaitu 0,361 dan nilai signifikansi dibawah $5 \%$ sehingga kesimpulannya adalah valid dan dapat digunakan untuk penelitian selanjutnya. Terakhir untuk variabel loyalitas pelanggan diperoleh nilai r-product moment hitung untuk pernyataan ke 1 yaitu 0,860 ; pernyataan ke 2 yaitu 0,893 ; pernyataan ke 3 yaitu 0,910; pernyataan ke 4 yaitu 0,934 . Hasil r-product moment hitung tersebut menunjukan hasil lebih besar dari $r$-product moment tabel, $\mathrm{n}=30$, $\alpha=5 \%$ yaitu 0,361 dan nilai signifikansi dibawah 5\% sehingga kesimpulannya adalah valid dan dapat digunakan untuk penelitian selanjutnya.

Tabel 1 Hasil Uji Reliabilitas Terhadap Variabel X1 (Bukti Fisik), X2 (Reliabilitas), X3 (Assurance), X4 (Daya Tanggap), X5 (Empati) dan Y (Loyalitas Pelanggan)

\begin{tabular}{ccc}
\hline Variabel & Cronbach's Alpha & N of Items \\
\hline X1 & .824 & 6 \\
X2 & .825 & 6 \\
X3 & .842 & 5 \\
X4 & .839 & 4 \\
X5 & .746 & 4 \\
Y & .841 & 5 \\
\hline
\end{tabular}

Sumber: Data Hasil Pengolahan Spss, 2019.

Hasil uji reliabilitas variabel penelitian ini ditunjukan pada Tabel 1. Berdasarkan tabel 1 diperoleh hasil Cronbach's Alpha untuk variabel Bukti Fisik sebesar 0,824 dan nilai Cronbach's Alpha lebih besar dari 0,6 maka data dinyatakan reliabel. Untuk variabel Reliabilitas diperoleh hasil Cronbach's Alpha sebesar 0,825 dan nilai Cronbach's Alpha lebih besar dari 0,6 maka data dinyatakan reliabel. Untuk variabel Assurance diperoleh hasil Cronbach's Alpha sebesar 0,842 dan nilai Cronbach's Alpha lebih besar dari 0,5 maka data dinyatakan reliabel. Nilai Cronbach's Alpha untuk variabel Daya Tanggap 
sebesar 0,839 dan nilai Cronbach's Alpha lebih besar dari 0,4 maka data dinyatakan reliabel. Untuk variabel Empati diperoleh hasil Cronbach's Alpha sebesar 0,746 dan nilai Cronbach's Alpha lebih besar dari 0,4 maka data dinyatakan reliabel. Untuk variabel Loyalitas Pelanggan diperoleh hasil Cronbach's Alpha sebesar 0,841 dan nilai Cronbach's Alpha lebih besar dari 0,5 maka data dinyatakan reliabel.

Tabel 2 Hasil Uji Normalis Data

\begin{tabular}{cccccccc}
\hline No & Kode Variabel & Rasio Skewness & Kurtosis & Tolerance & VIF & t & sig \\
\hline 1 & X1 & 2,099161 & $-0,2665$ & .684 & 1.463 & .688 & .709 \\
2 & X2 & 1,000596 & 0,40681 & .814 & 1.228 & .231 & .818 \\
3 & X3 & $-2,15952$ & 0,26286 & .708 & 1.412 & .625 & .534 \\
4 & X4 & $-0,3281$ & 0,27187 & .984 & 1.016 & 1.075 & .285 \\
5 & X5 & $-0,69226$ & 0,44102 & .997 & 1.003 & 1.131 & .261 \\
\hline
\end{tabular}

Sumber Data Primer Diolah

Tabel 2 menampilkan data hasil uji asumsi klasik. Variabel Bukti Fisik (X1) dengan rasio skewness 2,099161 dan rasio kurtosis -0,2665; variabel Reliabilitas (X2) dengan rasio skewness 1,000596 dan rasio kurtosis 0,40681; variabel Assurance (X3) dengan rasio skewness $-2,15952$ dan rasio kurtosis 0,26286; variabel Daya Tanggap (X4) dengan rasio skewness $-0,3281$ dan rasio kurtosis 0,27187 ; variabel Empati (X5) dengan rasio skewness -0,69226 dan rasio kurtosis 0,44102. Kelima variabel tersebut sesuai dengan nilai rasio skewness dan kurtosis berada diantara $-2 \mathrm{~s} / \mathrm{d}+2$ dan dinyatakan normal. Nilai Kritis $(\mathrm{Z})=$ Skewness $/-(6 / N)$. Z tidak boleh lebih dari 2,58 (sig. 1\%) dan 1,96 (sig. 5\%). Berdasarkan tabel 2, variabel Bukti Fisik (X1) diperoleh nilai toleransi sebesar 0,684 dan nilai VIF sebesar 1,463; variabel Reliabilitas (X2) diperoleh nilai toleransi sebesar 0,814 dan nilai VIF sebesar 1,228; variabel Assurance (X3) diperoleh nilai toleransi sebesar 0,708 dan nilai VIF sebesar 1,412; variabel Daya Tanggap (X4) diperoleh nilai toleransi sebesar 0,984 dan nilai VIF sebesar 1,016; variabel Empati (X5) diperoleh nilai toleransi sebesar 0,997 dan nilai VIF sebesar 1,003. Variabel X1, X2, X3, X4 dan X5 memperoleh nilai VIF dibawah 10 maka tidak terjadi multikolinearitas.

Berdasarkan tabel 2 diperoleh bahwa semua variabel independen secara statistic baik X1 (Bukti Fisik), X2 (Reliabilitas), X3 (Assurance), X4 (Daya Tanggap) dan X5 (Empati) mempunyai nilai signifikan $>0,05$ atau diatas 5\% dengan demikian dapat disimpulkan bahwa tidak terjadi heteroskedastisitas atau bersifat homoskedastisitas.

\section{Analisis Korelasi dan Regresi Berganda Untuk Data Penelitian}

Tabel 3. Hasil Analisis Regresi Berganda

\begin{tabular}{|c|c|c|c|c|c|c|}
\hline \multirow{2}{*}{\multicolumn{2}{|c|}{ Model }} & \multicolumn{2}{|c|}{$\begin{array}{l}\text { Unstandardized } \\
\text { Coefficients }\end{array}$} & \multirow{2}{*}{$\begin{array}{l}\text { Standardized } \\
\text { Coefficients } \\
\text { Beta }\end{array}$} & \multirow[t]{2}{*}{$\mathrm{T}$} & \multirow[t]{2}{*}{ Sig. } \\
\hline & & $\mathrm{B}$ & Std. Error & & & \\
\hline 1 & (Constant) & -2.450 & .353 & & -6.937 & .000 \\
\hline & Bukti Fisik (Tangible) & .471 & .052 & .476 & 9.134 & .000 \\
\hline & Reliabilitas & .076 & .025 & .091 & 3.041 & .003 \\
\hline & Assurance & -.004 & .005 & -.005 & -.790 & .432 \\
\hline & Daya Tanggap & .438 & .054 & 436 & 8.105 & .000 \\
\hline & Empati & -.001 & .005 & -.001 & -.150 & .881 \\
\hline
\end{tabular}

a. Dependent Variable: Loyalitas Pelanggan

Berdasarkan tabel 3 dapat ditentukan persamaan regresi berganda untuk penelitian ini sebagai berikut:

$\hat{Y}=-2,450+0,471 X_{1}+0,076 X_{2}-0,004 X_{3}+0,438 X_{4}-0,001 X_{5}+$ error

Berdasarkan persamaan regresi tersebut, jika:

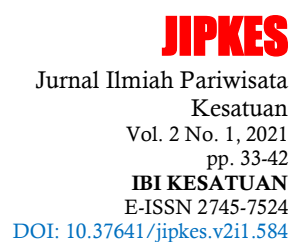


Golf Tourism

Customers

Satisfaction

$\underline{38}$

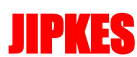

Jurnal Ilmiah Pariwisata Kesatuan

Vol. 2 No. 1, 2021

pp. $33-42$

IBI KESATUAN

E-ISSN 2745-7524

DOI: $10.37641 /$ jipkes.v2i1.584 a. Bukti Fisik $=$ Reliabilitas $=$ Assurance $=$ Daya Tanggap $=$ Empati $=0$, aka nilai dari Loyalitas Pelanggan nilainya sebesar $-2,450$.

b. Jika Bukti Fisik naik sebesar 1 (satu) satuan maka Loyalitas Pelanggan akan naik sebesar 0,471 jika variabel lain dianggap konstan.

c. Jika Reliabilitas naik sebesar 1 (satu) satuan maka Loyalitas Pelanggan akan naik sebesar 0,076 jika variabel lain dianggap konstan.

d. Jika Assurance naik sebesar 1 (satu) satuan maka Loyalitas Pelanggan akan naik sebesar -0,004 jika variabel lain dianggap konstan.

e. Jika Daya Tanggap naik sebesar 1 (satu) satuan maka Loyalitas Pelanggan akan naik sebesar 0,438 jika variabel lain dianggap konstan.

f. Jika Empati naik sebesar 1 (satu) satuan maka Loyalitas Pelanggan akan naik sebesar -0,001 jika variabel lain dianggap konstan.

Tabel 4. Koefisien Determinasi dan Koefisien Korelasi

\begin{tabular}{ccccc}
\hline Model & $\mathrm{R}$ & R Square & Adjusted R Square & Std. Error of the Estimate \\
\hline 1 & $.999^{\mathrm{a}}$ & .997 & .997 & .069
\end{tabular}

a. Predictors: (Constant), Empati, Reliabilitas, Assurance, Bukti Fisik (Tangible), Daya Tanggap

Berdasarkan pada tabel 4. dapat dijelaskan bahwa hubungan atau korelasi berganda pada seluruh variabel (Bukti Fisik, Reliabilitas, Assurance, Daya Tanggap, Empati dan Loyalitas Pelanggan), memiliki kekuatan hubungan yang sangat kuat mengacu pada tabel Sugiyono tahun 2007. Hal ini dilihat berdasarkan nilai koefisien korelasi berganda sebesar 0,999 . Perolehan nilai adjusted $r$-square sebesar 0,997 dapat dijelaskan bahwa variabel Bukti Fisik, Reliabilitas, Assurance, Daya Tanggap dan Empati mampu mempengaruhi atau menjelaskan keragaman (variabilitas) nilai dari Loyalitas Pelanggan sebesar 99,7\% sedangkan sisanya sebesar 3\% dipengaruhi atau dijelaskan oleh faktor lain atau variabel lain yang tidak diteliti.

Hasil Uji Hipotesis Penelitian

Tabel 5. Hasil Uji Hipotesis Penelitian Simultan

\begin{tabular}{ccccccc}
\hline & Model & Sum of Squares & Df & Mean Square & F & Sig. \\
\hline 1 & Regression & 169.338 & 5 & 33.868 & 7036.645 & $.000^{\mathrm{b}}$ \\
& Residual & .452 & 94 & .005 & & \\
& Total & 169.790 & 99 & & & \\
\hline
\end{tabular}

a. Dependent Variable: Loyalitas Pelanggan

b. Predictors: (Constant), Empati, Reliabilitas, Assurance, Bukti Fisik (Tangible), Daya

Tanggap

Berdasarkan tabel 5 hubungan antara Bukti Fisik, Reliabilitas, Assurance, Daya Tanggap dan Empati dengan Loyalitas Pelanggan diperoleh f-hitung 7036,645 dan lebih besar dari f-tabel $(\mathrm{df}=100-5.1=94, \alpha=5 \%)=1,66)$; Dan didukung oleh nilai signifikansi sebesar 0,000 dan lebih kecil dari $(\alpha=5 \%)=0,05$ dengan demikian H0 ditolak dan H1 diterima, Bukti Fisik, Reliabilitas, Assurance, Daya Tanggap dan Empati berpengaruh secara simultan terhadap Loyalitas Pelanggan, maka hipotesis 1 diterima.

Berdasarkan tabel 3 diperoleh t-hitung sebesar 9,134 dan nilai t-tabel ( $\mathrm{df}=100$ $5.1=94, \alpha=5 \%)=1,66)$ atau $(9,134>1,66)$, didukung nilai signifikansi 0,000 atau dibawah 0,05 atau 5\%, dengan demikian $\mathrm{H} 0$ ditolak dan $\mathrm{H} 2$ diterima, dapat disimpulkan bahwa Bukti Fisik berpengaruh secara signifikan terhadap Loyalitas Pelanggan, maka hipotesis penelitian 2 dinyatakan diterima. Berdasarkan tabel 3 diperoleh t-hitung sebesar 3,041 dan nilai t-tabel $(\mathrm{df}=100-5.1=94, \alpha=5 \%)=1,66)$ atau $(3,041>1,66)$, didukung nilai signifikansi 0,003 atau dibawah 0,05 (5\%), dengan demikian $\mathrm{H} 0$ ditolak dan H3 diterima, dapat disimpulkan bahwa 
Reliabilitas berpengaruh secara signifikan terhadap Loyalitas Pelanggan, maka hipotesis penelitian 3 dinyatakan diterima. Berdasarkan tabel 3 diperoleh t-hitung sebesar $-0,790$ dan nilai t-tabel $(\mathrm{df}=100-5.1=94, \alpha=5 \%)=1,66)$ atau $(-0,790<1,66)$, didukung nilai signifikansi 0,432 atau diatas $0,05(5 \%)$, dengan demikian H0 diterima dan $\mathrm{H} 4$ ditolak, dapat disimpulkan bahwa Assurance tidak berpengaruh secara signifikan terhadap Loyalitas Pelanggan, maka hipotesis penelitian 4 dinyatakan ditolak. Berdasarkan tabel 3 diperoleh t-hitung sebesar 8,105 dan nilai t-tabel $(\mathrm{df}=100-5.1=94, \quad \alpha=5 \%)=1,66)$ atau $(8,150>1,66)$, didukung nilai signifikansi 0,000 atau dibawah 0,05 (5\%), dengan demikian $\mathrm{H} 0$ ditolak dan $\mathrm{H} 5$ diterima, dapat disimpulkan bahwa Daya Tanggap berpengaruh secara signifikan terhadap Loyalitas Pelanggan, maka hipotesis penelitian 4 dinyatakan diterima. Berdasarkan tabel 3 diperoleh t-hitung sebesar $-0,150$ dan nilai t-tabel ( $\mathrm{df}=100$ $5.1=94, \alpha=5 \%)=1,66)$ atau $(-0,150<1,66)$, didukung nilai signifikansi 0,881 atau diatas 0,05 (5\%), dengan demikian $\mathrm{H} 0$ diterima dan $\mathrm{H6}$ ditolak, dapat disimpulkan bahwa Empati tidak berpengaruh secara signifikan terhadap Loyalitas Pelanggan, maka hipotesis penelitian 6 dinyatakan ditolak.

\section{Pembahasan}

Penelitian ini berdasarkan hasil uji statistik di atas hipotesis pertama yang berbunyi terdapat hubungan antara pengaruh Bukti Fisik, Reliabilitas, Assurance, Daya Tanggap dan Empati secara bersama-sama mempunyai hubungan dengan Loyalitas Pelanggan. Dengan demikian penelitian ini dapat membuktikan teori yang disampaikan oleh Stanton (2009) Gitosudarmo (2008), Kotler (2007), Saladin (2007) dan Kotler dan Keller (2009) yang intinya bahwa semua komponen jasa yang terdiri dari bukti fisik, reliabilias, assurance, daya tanggap dan empati secara bersama-samma harus ada dan diperhatikan supaya mampu memenuhi kepuasan dalam rangka konsumen mencapai loyalitas pelanggan.

Berdasarkan hasil uji analisis regresi berganda variabel X1 (Bukti Fisik) sebesar 0,471 artinya jika variabel Bukti Fisik naik sebesar satu satuan maka Y (Loyalitas Pelanggan) akan naik sebesar 0,471 jika variabel lain dianggap konstan. Dengan hasil dimana variabel tersebut berpengaruh positif dan signifikan terhadap Loyalitas Pelanggan, penelitian ini membuktikan teori yang disampaikan oleh Lovelock (2011) adalah sarana fisik merupakan suatu hal yang secara nyata turut mempengaruhi keputusan konsumen untuk membeli dan menggunakan produk jasa yang ditawarkan. Penelitian ini juga mendukung penelitian sebelumnya seperti yang dilakukan oleh Rinala et. al (2013), yang menunjukan hasil penelitian bahwa Kualitas Pelayanan (Bukti Fisik) mempunyai pengaruh yang positif dan signifikan terhadap Loyalitas Pelanggan. Maka PT. Karabha Digdaya (Emeralda Golf) perlu memperhatikan Bukti Fisik yang sudah berpengaruh secara positif dan signifikan terhadap Loyalitas Pelanggan.

Penelitian ini berdasarkan hasil uji statistic yang telah dilakukan di atas untuk hipotesis ketiga maka dapat disimpulkan bahwa Reliabilitas berpengaruh secara signifikan terhadap Loyalitas Pelanggan, maka hipotesis penelitian 3 dinyatakan diterima. Penelitian ini membuktikan teori yang disampaikan oleh Tjiptono (2009) Reliabilitas atau keandalan merupakan kemampuan perusahaan untuk melaksanakan jasa sesuai dengan apa yang telah dijanjikan secara tepat waktu. Pentingnya dimensi ini adalah kepuasan konsumen akan menurun bila jasa yang diberikan tidak sesuai dengan yang dijanjikan. Jadi komponen atau unsur dimensi reliabilitas ini merupakan kemampuan perusahaan dalam menyampaikan jasa secara tepat dan pembebanan biaya secara tepat. Penelitian ini juga mendukung penelitian sebelumnya seperti yang dilakukan oleh Suharno dan Shihab (2012),

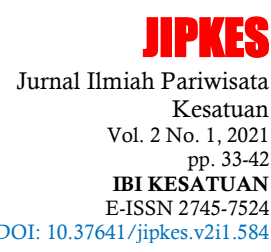

\section{$\longrightarrow$}


Golf Tourism

Customers

Satisfaction

40

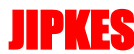

Jurnal Ilmiah Pariwisata

Kesatuan

Vol. 2 No. 1,2021

pp. $33-42$

IBI KESATUAN

E-ISSN 2745-7524

DOI: 10.37641 /jipkes.v2i1.584 yang menunjukan hasil penelitian bahwa Reliabilitas mempunyai pengaruh yang positif dan signifikan terhadap Loyalitas Pelanggan. Maka PT. Karabha Digdaya (Emeralda Golf) perlu memperhatikan Reliabilitas yang sudah berpengaruh secara positif dan signifikan terhadap Loyalitas Pelanggan.

Penelitian ini berdasarkan hasil uji statistik yang sudah dilakukan di atas terhadap hipotesis keempat dapat disimpulkan bahwa Assurance tidak berpengaruh secara signifikan terhadap Loyalitas Pelanggan, maka hipotesis penelitian 4 dinyatakan ditolak. Berdasarkan hasil uji analisis regresi berganda variabel X3 (Assurance) sebesar -0,004 artinya jika variabel Assurance naik sebesar satu satuan maka Y (Loyalitas Pelanggan) akan naik sebesar -0,004 jika variabel dianggap konstan. Dengan hasil dimana variabel tersebut tidak berpengaruh positif dan signifikan terhadap Loyalitas Pelanggan, maka Hipotesis 4 ditolak.

Penelitian ini berdasarkan hasil uji statistic yang dilakukan di atas terhadap hipotesis kelima dapat disimpulkan bahwa Daya Tanggap berpengaruh secara signifikan terhadap Loyalitas Pelanggan, maka hipotesis penelitian 4 dinyatakan diterima. Berdasarkan hasil uji analisis regresi berganda variabel X4 (Daya Tanggap) sebesar 0,438 artinya jika variabel daya tanggap naik sebesar satu satuan maka Y (Loyalitas Pelanggan) akan naik sebesar 0,438 jika variabel dianggap konstan. Dengan hasil dimana variabel tersebut berpengaruh positif dan signifikan terhadap Loyalitas Pelanggan, maka Hipotesis 3 diterima. Penelitian ini membuktikan teori yang disampaikan oleh Lupiyoadi (2014) Daya Tanggap (Responsiveness), yaitu suatu kemauan untuk memberikan pelayanan yang cepat dan tepat kepada pelanggan, dengan penyampaian informasi yang jelas. Membiarkan konsumen menunggu tanpa adanya suatu alasan yang jelas menyebabkan persepsi yang negatif dalam kualitas pelayanan. Penelitian ini juga mendukung penelitian sebelumnya seperti yang dilakukan oleh Janita, Suharyono, dan Kusumawati (2014) yang menunjukan hasil penelitian bahwa Kualitas Pelayanan (Daya Tanggap) mempunyai pengaruh yang positif dan signifikan terhadap Loyalitas Pelanggan. Maka PT. Karabha Digdaya (Emeralda Golf) perlu memperhatikan Daya Tanggap yang sudah berpengaruh secara positif dan signifikan terhadap Loyalitas Pelanggan.

Penelitian ini berdasarkan hasil uji statistic yang dilakukan di atas terhadap hipotesis enam dapat disimpulkan bahwa Empati tidak berpengaruh secara signifikan terhadap Loyalitas Pelanggan, maka hipotesis penelitian 6 dinyatakan ditolak. Berdasarkan hasil uji analisis regresi berganda variabel X5 (Empati) sebesar -0,001 artinya jika variabel Empati naik sebesar satu satuan maka $Y$ (Loyalitas Pelanggan) akan naik sebesar -0,001 jika variabel dianggap konstan. Dengan hasil dimana variabel tersebut tidak berpengaruh positif dan signifikan terhadap Loyalitas Pelanggan, maka Hipotesis 6 ditolak.

\section{PENUTUP}

Berdasarkan hasil yang telah diperoleh dari penelitian ini, dapat disimpulkan bahwaBukti Fisik, Reliabilitas, Assurance, Daya Tanggap dan Empati berpengaruh secara bersama-sama terhadap Loyalitas Pelanggan pada lapangan golf Emeralda. Besar pengaruh X1, X2, X3, X4, X5 terhadap Y adalah sebesar 7036,645. Pengaruhnya secara simultan signifikan. Bukti Fisik berpengaruh positif dan signifikan terhadap Loyalitas Pelanggan pada lapangan golf Emeralda. Besar pengaruh X1 terhadap Y adalah sebesar 0,471. Pengaruhnya variabel X1 signifikan. Reliabilitas berpengaruh positif dan signifikan terhadap Loyalitas Pelanggan pada lapangan golf Emeralda. Besar pengaruh X2 terhadap Y adalah 
sebesar 0,076. Pengaruhnya variabel X2 signifikan. Assurance tidak berpengaruh positif dan signifikan terhadap Loyalitas Pelanggan pada lapangan golf Emeralda. Besar pengaruh X3 terhadap Y adalah -0,004. Variabel X3 tidak berpengaruh signifikan. Daya Tanggap berpengaruh positif dan signifikan terhadap Loyalitas Pelanggan pada lapangan golf Emeralda. Besar pengaruh X4 terhadap Y adalah sebesar 0,438. Pengaruhnya variabel X4 signifikan. Empati tidak berpengaruh positif dan signifikan terhadap Loyalitas Pelanggan pada lapangan golf Emeralda. Besar pengaruh X3 terhadap Y adalah $-0,001$. Variabel X5 tidak berpengaruh signifikan.

Golf Tourism

Customers

Satisfaction

\section{DAFTAR PUSTAKA}

[1] Assael, H. 2004. Consumer Behavior: A Strategic Approach, 6th Ballester, E.D. Boston, MA: Houghton Mifflin Company.

[2] Cant, M. C., J. W. Strydom. C. J. Josste, dan P. J. du Plessis, eds. 2009. Marketing Management. $5^{\text {th }}$ ed. Claremont: Juta Academic.

[3] Chaney, David. 2003. Lifestyle. Jakarta : PT Raja Garfindo Persada.

[4] C. Mowen, Jhon. Michael, Minor. 2002. Perilaku Konsumen. Jakarta. Erlangga

[5] Cooper, R,G and E.J Kleinschmidth, 1987. What Makes a New Product a Winner: Succes Factors at The Project Level. R \& D Management.

[6] Engel, James F., Roger D. Blackwell, Paul W. Miniard. 2000. Perilaku Konsumen. Terjemahan F.X. Budianto. Jakarta : Binarupa Aksara

[7] Ferdinand, Augusty. 2011. Metode Penelitian Manajemen. Semarang: Badan Penerbit Universitas Diponegoro.

[8] Firmansyah, M. Anang. 2012. Perilaku Konsumen (Sikap dan Pemasaran). Yogyakarta. Penerbit: Deepublish.

[9] Ghozali, Imam. 2013. Aplikasi Analisis Multivariate Dengan Program SPSS, Edisi Keempat, Penerbit Universitas Diponegoro.

[10] Griffin, Jill. 2005. Customer Loyalty: Menumbuhkan \& Mempertahankan Kesetiaan Pelanggan. Jakarta: Erlangga

[11] Gunarathne, W, H, D, P. 2014. Relationship Between Service Quality and Customer Satisfaction in Sri Lanka Hotel Industry, International Journal of Scientific and Research Publications, Volume 4, pp 1-8.

[12] Keller, Kevin Lane, 1998, Strategic Brands Management: Building, Measuring, and Managing Brand Equity, New Jersey: Prentice Hall Inc.

[13] Kotler, Philip, Thomas, Hayes, dan Bloom Paul N. 2002. Marketing Professional Service. Prentice Hall International Press.

[14] Loudon, David L.;Bitta, Albert.J.Della. 1993. Consumer Behavior: Concepts and Application. Singapore: Mc Graw-Hill Book Company.

[15] Lovelock, Christoper, 1988. Managing Service : Marketing, Operations and Human Resources. London: Prentice Hall Int Inc.

[16] Mashadi, M., Nurachmad, E., \& Mulyana, M. (2019). Analisis Deskriptif Penilaian Website Perguruan Tinggi. JAS-PT (Jumal Analisis Sistem Pendidikan Tinggi Indonesia), 3(2), 97-106.

[17] Mulyana, M. (2012). Consumer Behaviour: Sukses Dengan Memahami Konsumen.

[18] Nugroho J.Setiadi, 2003. Perilaku Konsumen (Konsep dan Implikasi Untuk Strategi dan Penelitian Pemasaran). Yogyakarta: Andi.

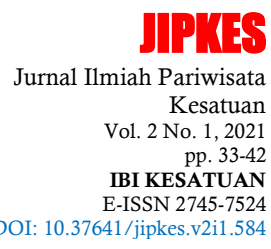


Golf Tourism

Customers

Satisfaction

$\underline{42}$

\section{JPYKS}

Jurnal Ilmiah Pariwisata

Kesatuan

Vol. 2 No. 1,2021

pp. 33-42

IBI KESATUAN

DOI: 10.37641 /jipkes.v2i1.584
[19] Parasuraman, Valarie A. Z. and Berry. 2002. Delivering Service Quality. McMilan, New York.

[20] Pride, William dan O.C. Ferrell. 2010. Marketing. 15th ed. Canada: South Western Cengag Learning.

[21] Read, D dan B. V. Leeuwen. 2010. "Pavlovian Processesin Customer Choice : The Physical Presence of a Good Increases Willingness-to-pay". American Economic Review, 100. 1-8.

[22] Schiffman, L. G., \& Kanuk, L. L. 2008. Perilaku Konsumen Edisi Ketujuh. Jakarta: PT. Indeks Group Media.

[23] Shimp, Terence, A. 2007. Integrated Marketing Communication In Advertising and Promotion. Edisi Ketujuh. New York, Mc Graw Hill.

[24] Sumarwan, Ujang. 2011. Perilaku Konsumen, Teori dan Penerapannya dalam Pemasaran. Bogor: Ghalia Indonesia.

[25] Vivi Ristanti, Muchsin Saggaff, Endi. 2011. Pengaruh Dimensi Kualitas Pelayanan dan Kepuasan Terhadap Loyalitas Pelanggan. Jurnal Manajemen dan Bisnis. Vol.9 No.17

[26] Steven Darwin, Yohanes Sondang Kunto. 2014. Analisis Pengaruh Kualitas Layanan Terhadap Loyalitas Pelanggan dengan Kepuasan dan Kepercayaan Pelanggan. Jurnal Manajemen Pemasaran. Vol 2, No.1.

[27] Defrian, Mulyaningsih. 2013. Reliabilitas Mempengaruhi Kepuasan Pasien Terhadap Pelayanan Kesehatan. Jurnal Ilmu Keperawatan. Vol.10 No.2

[28] Dwi Aryani, Febrina Rosinta. 2010. Pengaruh Kualitas Layanan terhadap Kepuasan Pelanggan dalam Membentuk Loyalitas Pelanggan. Jurnal Ilmu Administrasi dan Organisasi. Vol 17. No 2. Hal 114-126

[29] Inka, Suharyono, Andriani. 2014. Pengaruh Kualitas Produk dan Kualitas Pelayanan terhadap Kepuasan Pelanggan dalam Membentuk Loyalitas Pelanggan. Jurnal Administrasi Bisnis. Vol.15 No.1.

[30] Parasuraman, A. 1997, Reflections on Gaining Competitive Advantage Through Costumer Value. Journal of the Academy of Marketing Science, Vol.64,p.1240.

[31] Lidya, Lisbeth, Agusta. 2013. Kualitas Produk, Strategi Promosi Dan Harga Pengaruhnya Terhadap Keputusan Pembelian. Jurnal EMBA. Vol.1 No.4, Hal 2336-2346

[32] Narso Suharno, Muchsin Saggaff. 2012. Pengaruh Dimensi Reliabilitas, Dimensi Tangibel dan Dimensi Empati Terhadap Loyalitas Pasien. Jurnal Manajemen dan Bisnis. Vol.10 NO.19

[33] Nurhayati, Risky. 2011. Pengaruh Kualitas Produk dan Harga Terhadap Loyalitas Pelanggan. Jurnal Universitas Pembangunan Nasional "Veteran" Yogyakarta.

[34] Hidayat, Rachmad. 2009. Pengaaruh Kualitas Layanan, Kualitas Produk dan Nilai Nasabah Terhadap Kepuasan dan Loyalitas Nasabah Bank Mandiri. Jurnal Manajemen dan Kewirausahaan. Vol.11 No.1 